for technical help; the department of medical illustration for the figure; Miss J Mitchell, dietetic department, for organising the standard meals; Mrs L Connolly for typing the manuscript; and Squibb (UK) for financial support.

\section{References}

' Leren P, Helgeland A, Holme I, Foss PO, Hjermann I, Lund-Larsen PG. Effect of propranolol and prazosin on blood lipids. The Oslo study. Lancet 1980;ii:

${ }^{2}$ Anonymous. Antihypertensive drugs, plasma lipids and coronary disease [Editorial ]. Lancet 1980;ii:19-20

of total serum cholesterol. Clin Chem $1974 ; 20: 470-5$.

- Berstein M, Scholnick HR, Morfin R. Rapid method for the isolation of lipo proteins from human serum by precipitation with polyamines. $\mathcal{J}$ Lipid Res 1970 $11: 583-95$.

${ }^{5}$ Bucolo G, David H. Quantitative determination of serum triglycerides by the use

of enzymes. Clin Chem 1973;19:476-82.
Wahlefeld AW. Triglycerides. Determination after enzymatic hydrolysis. In Bergmeyer HU, ed. Methods in enzymatic analyses. 2nd ed. London: Academic

' Friedewald WT, Levy RI, Fredrickson DS. Estimation of the concentration of lowdensity lipoprotein cholesterol in plasma without use of the preparative ultra-

' Ivashnik E. Fluorometric determination of nadolol in human serum and urine. f Pharm Sci 1977;66:1168-72.

period cross-over clinical trial. Br $\mathcal{f}$ Clin Pharmaco

10 Cochran WG. Analysis of covariance: its nature and uses. Biometrics $1957 ; 13$ : 261-81.

Dixon WJ, Brown MB, eds. Biomedical computer programs $P$ series. London: University of California Press, 1979 .

2 Gibbons DO, Lant A, Ashford A, Collins RF, Pinder S. Comparative effects of acebutolol and practolol on the lipolytic response to isoprenaline. $\mathrm{Br} \mathcal{J}$ Clin Pharmacol 1976;3:177-84.

$13 \mathrm{Harms} \mathrm{HH}$, De Vente J, Zaagsma J. $\beta$-adrenoceptor blocking agents and lipolysis. Br $\mathcal{F}$ Clin Pharmacol 1982;13:181-6S.

14 Pinter EJ, Pattee CJ. Effect of $\beta$-adrenergic blockade on resting and stimulated

fat mobilisation $\mathrm{F}$ Clin Endocrinol Metab

pay J, Simpson N, Metcalfe J, Page RL. Metabolic consequences of atenolol and
propranolol in treatment of essential hypertension. Br Med $\mathcal{f} 1979 ; \mathrm{i}: 77-80$.
${ }^{16}$ Lehtonen A, Viikari J. Long-term effect of sotalol on plasma lipids. Clin Sci $1979 ; 57: 405-7 S$

17 Day JL, Metcalfe J, Simpson CN. Adrenergic mechanisms in control of plasma lipid concentrations. $\mathrm{Br}$ Med $\mathcal{f}$ 1982;284:1145-8.

${ }^{8}$ Nilsson A, Hanson BG, Hokfeldt B. Effect of metoprolol on blood glycerol, free fatty acids, triglycerides and glucose in relation to plasma catecholamines in hypertensive patients at rest and following submaximal work. Eur $\mathcal{f}$ Clin

Pharmacol 1978;13:5-8.
19irnbaum J, Di Bianco R, Becker KL, et al. Glucose and lipid metabolism during acebutolol and propranolol therapy of angina in non-diabetic patients. Clin Pharmacol Ther 1983;33:294-300

${ }^{\circ}$ England JP, Hau AD, Shaw J. $\beta$-adrenoceptor blocking agents and lipid metabolism. Clin Sci Mol Med 1978;55:323-4S.

Waal-Manning HJ. Metabolic effects of $\beta$-adrenoceptor blockers. Drugs 1976; 11, suppl $1: 121-6$

administration 25:1071-5.

${ }^{23}$ Bauer JH, Brooks CS, Weinstein I, et al. Effects of diuretic and propranolol on plasma lipoprotein lipids. Clin Pharmacol Ther 1981;30:35-43.

${ }^{44}$ Kristensen BO. Effect of long-term treatment with beta blocking drugs on plasma

lipids and lipoproteins. $\mathrm{Br} M e d \mathcal{F} 1981 ; 283: 191-2$.
as Ballantyne P, Ballantyne $\mathrm{FC}, \mathrm{McMurdo} \mathrm{M}$. Effect of slow oxprenolol and a combination of slow oxprenolol and cyclopenthiazide on plasma lipoproteins. Atherosclerosis $1981 ; 39: 301-6$

${ }^{3}$ Huttunen JK, Ehnholm C, Kekki M, Nikkila EA. Post-heparin plasma lipoprotein lipase and hepatic lipase in normal subjects and in patients with hypertriglyceridaemia : correlations to sex, age and various parameters of triglyceride metabo-

27 Barboriak JJ, Friedberg HD. Propranolol and hypertryglyceridaemia. Atherosclerosis $1973 ; 17: 31-3$.

"8 Bloom SR, Johnston RH, Park DM, Rennie MJ, Sulaiman WR. Difference in the metabolic and hormonal response to exercise between racing cyclists and untrained individuals. $\mathcal{F}$ Physiol (Lond) 1976;258:1-18.

20 Lithell H, Cedermark M, Friberg J, Tesch P, Karlsson J. Increase of lipoprotein lipase activity in skeletal muscle during heavy exercise. Relation to epinephrine excretion. Metabolism 1981;30:1130-4.

${ }^{30}$ Hooper PL, Woo W, Visconti L, Pathak DR. Terbutaline raises high density lipoprotein cholesterol levels. $N$ Engl f Med $1981 ; 305: 1455-7$.

${ }^{31}$ Lewis B. The lipoproteins: predictors, protectors and pathogens. $\mathrm{Br} \mathrm{Med} \mathfrak{f}$ 1983;287:1161-4.

$32 \mathrm{Kekki} M$. Lipoprotein-lipase action determining high density lipoprotein cholesterol in adult normolipaemics. Atherosclerosis $1980 ; 37: 3-50$

3 Lennon DLF, Stratman FW, Shrago E, et al. Total cholesterol and HDL cholesexen and women.

(Accepted 11 April 1984)

\title{
The dysplastic naevus syndrome and endocrine disease
}

\author{
S J ADAMS, MALCOLM H A RUSTIN, T W E ROBINSON, D D MUNRO
}

\begin{abstract}
Members of two different families were found to have the dysplastic naevus syndrome and coexistent endocrine abnormalities. The dysplastic naevus syndrome is probably inherited as an autosomal dominant trait and has been associated with other primary malignancies. This is the first time that it has been described in association with endocrine abnormalities.
\end{abstract}

\section{Introduction}

Dysplastic naevi are clinically and histologically distinct skin lesions that may be formal histogenetic precursors of cutaneous melanoma. First described by Cawley in 1952,1 they have subsequently been reported as the $\mathrm{BK}$ mole syndrome and the familial atypical mole malignant melanoma syndrome.

Department of Dermatology, University College Hospital, London WC1E 6AU

S J ADAMS, MB, MRCP, senior registrar

T W E ROBINSON, MA, FRCP, consultant dermatologist

Department of Dermatology, St Bartholomew's Hospital, London EC1

MALCOLM H A RUSTIN, BSC, MRCP, registrar

D D MUNRO, MD, FRCP, consultant dermatologist

Correspondence to: Dr S J Adams.
Characteristic features of the syndrome are a family history of malignant melanoma and multiple large melanocytic naevi with irregular outlines and variegated pigmentation. Histological examination shows a compound melanocytic naevus with atypical melanocytic hyperplasia, fibroplasia, new vessel formation, and a mixed lymphocytic and macrophage infiltrate in the dermis. Although the associated malignant melanoma is assumed to arise from the dysplastic naevi, MacKie observed melanoma arising in clinically normal skin and consequently suggested an alternative mechanism in the "activated and expanded melanocyte syndrome." 2

The dysplastic naevus syndrome is probably inherited as an autosomal dominant trait, and a link with other primary malignancies has been reported. ${ }^{3}$ An association with endocrine abnormalities has hitherto not been described, but we report here on two families with the dysplastic naevus syndrome and malignant melanoma who had coexistent multiple endocrine abnormalities.

\section{Case reports}

\section{FAMILY 1}

The eldest girl of four siblings was diagnosed as having multiple endocrine adenopathy with hyperparathyroidism and a pancreatic islet cell tumour. She died several years later from metastatic malignant melanoma after previous local excision of malignant melanoma. During a routine follow up of the family primary hyperparathyroidism was diagnosed in her twin sisters, one of whom had undergone 
excision of a parathyroid adenoma. These sisters were subsequently noted to have large irregular pigmented naevi on their trunks, arms, and legs. These naevi were clinically and histologically consistent with lesions of the dysplastic naevus syndrome.

The father of the three girls also had primary hyperparathyroidism and in 1982 noted that a mole had become indurated and irritant. Histological examination confirmed the diagnosis of nodular malignant melanoma. In neither the father nor the eldest daughter had there been histological evidence of a naevus preceding the malignant melanoma and in neither had clinically abnormal naevi been reported. A fourth sibling was completely healthy.

\section{FAMILY 2}

A 15 year old girl presented in March 1983 with a two year history of increasing pigmentation on her wrists, lips, and backs of her hands. She had suffered from eczema and asthma since the age of 2 ; the eczema had been treated with a moderately potent topical steroid and the asthma with a salbutamol inhaler used intermittently. The dysplastic melanocytic naevus syndrome had been diagnosed in the mother in $1973,{ }^{4}$ and the mother's father had died from a malignant melanoma that had arisen in a naevus. A maternal aunt had type II diabetes mellitus, and a maternal uncle had pernicious anaemia and type II diabetes mellitus.

Examination of the girl showed hyperpigmentation over the extensor aspects of the joints of both hands and on the fronts of both wrists. The nipples, the buccal mucous membranes, and the linea nigra were also hyperpigmented. There was a postural fall of $15 \mathrm{~mm} \mathrm{Hg}$ in the systolic blood pressure $(110 / 60 \mathrm{~mm} \mathrm{Hg}$ supine, $95 / 60 \mathrm{~mm} \mathrm{Hg}$ standing). Addison's disease was diagnosed when her plasma cortisol concentration at 0900 was found to be $150 \mathrm{nmol} / 1(4.9 \mathrm{pg} / 100 \mathrm{ml})$ (normal range $170-700 \mathrm{nmol}(5 \cdot 6-22 \cdot 9 \mathrm{pg} / 100 \mathrm{ml}$ ) and her plasma adrenocorticotrophic hormone concentration at 0900 was $1605 \mathrm{ng} / 1$ (normal $10-80 \mathrm{ng} / \mathrm{l}$ ) and a long test with tetracosactrin acetate ( $2 \mathrm{mg}$ Synacthen Depot intramuscularly) did not yield a response. Antiadrenal antibodies were present and her HLA type was homozygous for A1, B8, C7, and DR3.

\section{Discussion}

The multiple endocrine adenopathy syndrome, in which primary hyperparathyroidism is often a presenting feature, and the autoimmune polyglandular syndrome, in which Addison's disease is a constant feature, are both syndromes of familial endocrine abnormalities. They are inherited in an autosomal dominant mode, and the polyglandular syndrome has been linked with the HLA system. ${ }^{5}$ Multiple endocrine adenopathy may present with tumours of the pancreatic islet cells, neurofibromatosis, and thyroid medullary carcinoma.

The dysplastic naevus syndrome is similarly dominantly inherited, and the association between two dominantly inherited syndromes may be fortuitous. The association between the dysplastic naevus syndrome and families susceptible to cancer has been well reported, ${ }^{3}$ but no reports have previously been published of a link with multiple endocrine disease. Members of both families reported on here, however, presented with multiple endocrine abnormalities and the dysplastic naevus syndrome.

We thank Dr D Brenton, University College Hospital, for allowing us to report on his patient.

\section{References \\ Cawley EP. Genetic aspects of malignant melanoma. Arch Dermatol 1952;65: \\ $440-50$.
MacKie RM. Multiple melanoma and atypical melanocytic naevi-evidence of an activated and expanded melanocytic system. Br f Dermatol 1982;107:621-9. Lynch HT, Fusaro RM, Pester J, et al. Tumour spectrum in the FAMM syndrome. Br F Cancer 1981;44:553-60. \\ Munro DD. Multiple active junctional naevi with family history of malignant melanoma. Proc R Soc Med 1974;67:594-5. \\ disease asso of autoimmune Addison's dular autoimmune (PGA) syndromes. \\ Accepted 9 April 1984)}

\begin{abstract}
Concentrations of sodium, chlorine, potassium, chromium, iron, cobalt, zinc, rubidium, silver, caesium, and selenium in cerebrospinal fluid from 14 control subjects and 20 patients with motor neurone disease were measured by in vitro neutron activation analysis. No statistically significant correlation was found between the concentrations of any two elements other than sodium and chlorine in either the patient or control

Department of Medical Neurology, Northern General Hospital, Edinburgh EH5 2DQ

J D MITCHELL, MB, MRCP, senior registrar

B PENTLAND, BSC, MRCP, consultant

Scottish Universities Research and Reactor Centre, East Kilbride, Glasgow G75 0QU

I A HARRIS, CCHEM, MRSC, research assistant

B W EAST, PHD, lecturer

Correspondence to: Dr J D Mitchell.
\end{abstract}

group $(\mathbf{r}=0.9905 ; p<0.001)$. The mean cobalt concentration was significantly lower in the patients $(p=0.0015)$. No other statistically significant difference was shown.

The relevance of this finding was examined in relation to current concepts of the pathogenesis of motor neurone disease and the role of cobalt in cellular metabolism.

\section{Introduction}

Although the aetiology and pathogenesis of motor neurone disease remain unknown, repeated attempts have been made to implicate heavy metals, notably lead and mercury. While lead poisoning may occasionally produce a syndrome resembling motor neurone disease which improves with chelation therapy, patients with the true disease clearly do not respond to such treatment. ${ }^{1}$ Other studies have also tried to show a toxic role for elements such as selenium, manganese, aluminium, calcium, and copper in motor neurone disease. ${ }^{12}$ No clear evidence has emerged.

In view of the continuing possibility of a metabolic cause for motor neurone disease we have studied the concentrations 